\title{
Classification and Analysis of Pathology of the Long Head of the Biceps Tendon in Complete Rotator Cuff Tears
}

\author{
Chien-Hao Chen, MD; Chih-Hwa Chen, MD; Chih-Hsiang Chang, MD; Chun-I Su, MD; \\ Kun-Chung Wang, MD; I-Chun Wang, MD; Hsien-Tao Liu, MD; Chung-Ming Yu, MD; \\ Kuo-Yao Hsu', MD
}
Background: Pathology of the long head of the biceps tendon (LHB) is commonly associ- ated with rotator cuff tears (RCTs). Superior labral anterior-posterior (SLAP) lesions can also occur with RCTs. The purpose of this study was to include SLAP lesions as part of LHB pathology in surgical cases of RCT and define the role of SLAP lesions in RCTs.
Methods: We retrospectively evaluated clinical data from 176 cases of complete RCT undergoing surgery. During surgery, the LHB was arthroscopically exam- ined. A modified 6-type classification was used to describe the LHB patholo- gy in these cases: tendinitis, subluxation, dislocation, partial tear, complete rupture and SLAP lesions. The relationship of LHB pathology to different characteristics of RCTs was statistically analyzed.
Results: $\quad$ Of RCT cases, 33\% had Type 1 (tendinitis), $11 \%$ had Type 2 (subluxation), 9\% had Type 3 (dislocation), 16\% had Type 4 (partial tear), $7 \%$ had Type 5 (complete rupture) and 6\% had Type 6 (SLAP) lesions. The remaining 18\% of cases had no obvious LHB pathology. LHB pathology were associated with RCTs of a long duration (>3 months), large area $\left(>5 \mathrm{~cm}^{2}\right)$, and multi- ple or subscapularis tendon involvement. Seventy four percent of patients with affected shoulders underwent simultaneous surgery for both LHB pathology and RCTs.

Conclusion: Most patient with RCTs with chronic, massive, and multiple or subscapularis tendon involvement also had LHB injury. SLAP lesions, which we classified as a subgroup of LHB pathology, should be identified during rotator cuff surgery and treated appropriately.

(Chang Gung Med J 2012;35:263-70)

Key words: long head of biceps tendon, rotator cuff tears, SLAP lesions

$\mathrm{F}$ ull thickness rotator cuff tears (RCTs) is one of the most common lesions affecting the shoulder joint. Conditions associated with RCTs include acromioclacivular arthritis, pathology of the long head of the biceps tendon (LHB), and labral lesions. The anatomic nature of the rotator cuff and LHB means that these two structures are usually injured at the same time, or as a consequence of injury to either

From the Department of Orthopaedic Surgery, Chang Gung Memorial Hospital at Keelung; 'Department of Orthopaedic Surgery, Chang Gung Memorial Hospital at Linkou, Chang Gung University College of Medicine, Taoyuan, Taiwan.

Received: July 11, 2011; Accepted: Dec. 7, 2011

Correspondence to: Dr. Chih-Hwa Chen, Department of Orthopaedic Surgery, Chang Gung Memorial Hospital at Keelung. 222, Maijin Rd., Anle District, Keelung City 204, Taiwan (R.O.C.) Tel: 886-2-24313131 ext. 2613; Fax: 886-2-24332655;

E-mail: afachen@doctor.com 
one. In animal models, the mechanical properties of the LHB are altered in the presence of RCTs. ${ }^{(1)}$ Impingement of the LHB and the supraspinatus tendon or biceps instability caused by tears of the subscapularis tendon could result in biceps tendon pathology. LHB lesions were found in $76 \%$ of patients receiving arthroscopic repair of RCTs. ${ }^{(2)}$ Gill et al reported a prevalence of 5\% of partial tears of the LHB in 847 shoulder arthroscopic examinations, and of those, $85 \%$ were associated with RCTs. ${ }^{(3)}$ The overlapping symptoms of this two lesions, such as shoulder pain and night pain, may often be wrongly explained as a RCTs alone. Since these two different lesions can occur together, any LHB pathology should be identified and treated at the same time as RCTs repair to prevent compromise of the clinical outcome. Chen et al. has postulated a simplified classification of LHB lesions to emphasize its association with RCTs. ${ }^{(2)}$ This classification includes five types of LHB pathology, tendinitis, subluxation, dislocation, partial tear and complete rupture.

Reviewing the research, Miller and Savoie found that $74 \%$ of individuals with full-thickness RCTs had associated intraarticular lesions, with labral tears being the most commonly associated disorder. ${ }^{(4)}$ Gartsman et al. performed arthroscopic examination of the glenohumeral joint in 200 shoulders in 195 consecutive patients before arthroscopic rotator cuff repair, noting superior labral anteriorposterior (SLAP) lesions in five patients. ${ }^{(5)}$ To our knowledge, no classification system has yet been developed that includes SLAP lesions as a type of biceps pathology associated with RCTs. In our study, we classified SLAP lesions as a subgroup of LHB pathology in order to comprehensively demonstrate their relationship with RCTs and establish the role of SLAP lesions in RCTs.

\section{METHODS}

Between 1993 and 2005, 176 shoulders with complete, full-thickness RCTs receiving arthroscopic examination and rotator cuff repair at our institution were included in this retrospective study. There were 102 men and 74 women. The average age at the time of surgery was 56.2 years (range, 23-78 years). The mechanism of rotator cuff injury (traumatic or degenerative) and the time interval from the accident or onset of symptoms to surgical treatment were recorded. Traumatic mechanisms included motor vehicle accidents, sports injuries, and falls onto the upper extremity or shoulder. Injuries in older patients (> 60 years) with a chronic and insidious onset of symptoms which could not be attributed to any traumatic event were classified as degenerative. All patients presented with varying degrees of functional limitation, including shoulder pain, weakness and a decreased range of motion. The study was approved by the hospital Institutional Review Board.

All patients received routine radiographic examinations (anteroposterior and axillary view) and magnetic resonance arthrograms of the shoulder prior to surgery. Diagnostic arthroscopy was performed initially, followed by open, mini-open, or arthroscopic rotator cuff repair as indicated. Rotator cuff pathology and associated injuries to the LHB and labrum were recorded during the operation. To better evaluate LHB pathology, we applied a 6-type classification, including comments on the biceps anchor, location and integrity, to describe the lesions, modified from that presented by Chen et al. in 2005. ${ }^{(2)}$ Lesions were classified as follows: Type 1 (biceps tendinitis), Type 2 (subluxation of the biceps tendon), Type 3 (dislocation of the biceps tendon), Types 4 and 5 (partial and complete biceps tendon tears, respectively) and Type 6 (SLAP lesions) (Figure). The surgical procedures for all RCT cases and each type of LHB pathology, if present, were recorded. The duration
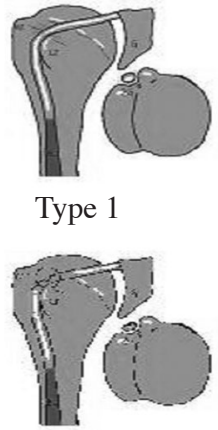

Type 4
Type 1

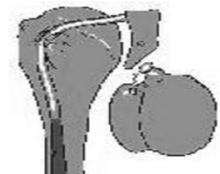

Type 2

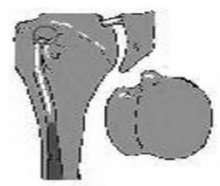

Type 5

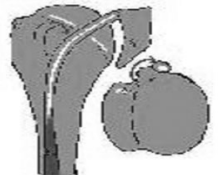

Type 3

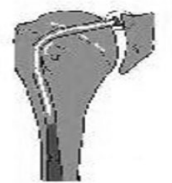

Type 6
Figure We defined the six types of pathology of the long head of the biceps associated with rotator cuff tears as biceps tendinitis (Type 1), subluxation of the biceps tendon (Type 2), dislocation of the biceps tendon (Type 3), partial biceps tendon tears (Type 4), complete biceps tendon tears (Type 5) and superior labral anterior-posterior (SLAP) lesions (Type 6). 
(more or less than 3 months), size (larger or smaller than $5 \mathrm{~cm}^{2}$ ), and the involved tendon(s) of RCTs in different types of LHB pathology (or intact biceps) tendon were recorded. RCTs $>3$ months were defined as chronic and those $>5 \mathrm{~cm}^{2}$ were defined as massive tears.

\section{Principles and indications for treating LHB pathology in RCTs}

In our patients, surgical treatment of concomitant LHB pathology in rotator cuff repair included debridement, tenotomy, tenodesis and repair of lesion structures. In general, we performed debridement for Types 1 and 2 LHB pathology. But if a reparable transverse humeral ligament was identified in Type 2 LHB pathology, we tried to repair it. For Type 3 LHB pathology, we performed a tenotomy or tenodesis, depending on the patient's age and activity level. We choose a tenotomy for patients $>50$ years or those who had lower functional demands; otherwise, a tenodesis was preferred. For partial tear LHB (Type 4), if the torn area was grossly $>50 \%$, the principle of treatment was the same as for biceps dislocation. If the torn area was $<50 \%$, we performed only debridement and partial resection. In Type 5 LHB pathology, a tenodesis was performed only for those with retrievable tendon stumps. For type 6 , we performed debridement for SLAP type I, III, and IV (if the area involved was $<30 \%$ of the LHB thickness) lesions. Suture anchor repair was indicated for all SLAP type II lesions.

\section{Statistical analysis}

The incidence of LHB pathology for different types of RCTs was calculated and statistically analyzed using SPSS software version 12. (SPSS Inc., Chicago, IL, U.S.A.). The Pearson chi-square test was used to examine the differences in the incidence of LHB pathology by varying degree of RCTs. A $p$ value of $<0.05$ was considered significant.

\section{RESULTS}

In these 176 cases, rotator cuff repairs were performed in 146 shoulders, debridement in 16 shoulders, tendon transfer in eight shoulders, and a shift to shoulder replacement with a prosthesis in six shoulders. The complete RCTs resulted from trauma in 93 shoulders $(52 \%)$ and degeneration in the remaining
$83(48 \%)$. Ninety-five (54\%) cases had chronic RCTs. Sixty-one (35\%) RCTs were massive tears $\left(>5 \mathrm{~cm}^{2}\right)$.

\section{Incidence of LHB pathology in RCTs}

In our studied group of complete RCTs, $82 \%$ of cases were associated with LHB (144/176 shoulders). Furthermore, $72 \%$ (67 shoulders) of traumatic cases and 92\% (77 shoulders) of degenerative cases had concomitant LHB pathology. Among the 144 cases with combined LHB pathology, 40\% (58 shoulders) were classified as Type 1, 13\% (19 shoulders) as Type 2, $11 \%$ (16 shoulders) as Type 3, 20\% (29 shoulders) as Type 4, 9\% (12 shoulders) as Type 5 and 7\% (10 shoulders) as Type 6. In the Snyder classification, the ten cases with SLAP lesions were further diagnosed as three cases of type I, two each of types II and III, and three of type IV. The average age of patients with both SLAP lesions and RCTs was 48.2 years. The overall incidence of SLAP lesions among the 176 cases in our study was $6 \%$ (10/176) (Table 1).

We observed that the characteristics of the RCTs significantly influenced the incidence of LHB pathology. For example, patients who had RCTs for a long duration (e.g., > 3 months) were more likely to have concomitant LHB pathology compared with those who presented with RCTs $<3$ months (97\% vs. $64 \%, p<0.001)$. Furthermore, patients with large RCTs (e.g., $>5 \mathrm{~cm}^{2}$ ) were more likely to have combined LHB pathology than those with small $(<5$ $\left.\mathrm{cm}^{2}\right)$ ones $(93 \%$ vs. $76 \%, p=0.004)$ (Table 1$)$. Of the 176 cases of complete RCTs, $52 \%$ (92 shoulders) were single tendon tears. These cases were less likely to have LHB pathology than those with multiple tears $(71 \%$ vs. $94 \%, p<0.001)$ (Table 2$)$.

\section{Biceps instability and subscapularis tendon tears}

We observed a higher rate of LHB pathology in the group with torn subscapularis tendons than in those with intact ones (97\% vs. $75 \%, p<0.001)$. The incidence of biceps instability (subluxation or dislocation) for those with complete RCTs was $20 \%$ (35/176 shoulders). We observed that if the subscapularis tendon was torn, biceps instability was observed in $48 \%$ (27/56 shoulders) of cases with LHB pathology. By contrast, if the subscapularis tendon was intact (through RCTs), only 9\% (8/88 shoul- 
Table 1. LHB Pathology and Duration and Size of Tears in Patients with Complete Rotator Cuff Tears

\begin{tabular}{|c|c|c|c|c|c|c|c|c|c|c|}
\hline Status of LHB & Type 1 & Type 2 & Type 3 & Type 4 & Type 5 & Type 6 & $\begin{array}{c}\text { LHB } \\
\text { pathology }\end{array}$ & $\begin{array}{l}\text { Normal } \\
\text { biceps }\end{array}$ & total & $p$ value \\
\hline Cases No. & $58(40 \%)$ & $19(13 \%)$ & $16(11 \%)$ & $29(20 \%)$ & $12(9 \%)$ & $10(7 \%)$ & $144(82 \%)$ & $32(18 \%)$ & 176 & \\
\hline \multicolumn{11}{|c|}{ Rotator cuff tears time } \\
\hline$>3$ months & 40 & 12 & 10 & 17 & 7 & 6 & $92(97 \%)$ & $3(3 \%)$ & 95 & \multirow{2}{*}{$<0.001$} \\
\hline$<3$ months & 18 & 7 & 6 & 12 & 5 & 4 & $52(64 \%)$ & $29(36 \%)$ & 81 & \\
\hline \multicolumn{11}{|c|}{ Size of rotator cuff tear } \\
\hline$>5 \mathrm{~cm}^{2}$ & 8 & 11 & 9 & 15 & 7 & 7 & $57(93 \%)$ & $4(7 \%)$ & 61 & \multirow{2}{*}{0.004} \\
\hline$<5 \mathrm{~cm}^{2}$ & 50 & 8 & 7 & 14 & 5 & 3 & $87(76 \%)$ & $28(24 \%)$ & 115 & \\
\hline
\end{tabular}

Abbreviations: LHB: long head of the biceps; RCT: rotator cuff tear.

Table 2. Involved Rotator Cuff Tendons in Six Types of LHB Pathology in Patients with Complete Rotator Cuff Tears

\begin{tabular}{|c|c|c|c|c|c|c|c|c|c|c|}
\hline Status of LHB & Type 1 & Type 2 & Type 3 & Type 4 & Type 5 & Type 6 & $\begin{array}{c}\text { LHB } \\
\text { pathology }\end{array}$ & $\begin{array}{c}\text { Normal } \\
\text { biceps }\end{array}$ & total & $p$ value \\
\hline Single rotator cuff tendon tear & & & & & & & $65(71 \%)$ & $27(29 \%)$ & 92 & $<0.001$ \\
\hline Supraspinatus & 38 & 2 & 1 & 9 & 0 & 2 & & & & \\
\hline Subscapularis & 1 & 0 & 3 & 6 & 1 & 2 & & & & \\
\hline Multiple rotator cuff tendons tears & & & & & & & $79(94 \%)$ & $5(6 \%)$ & 84 & \\
\hline Supra. + Infra. & 13 & 2 & 3 & 9 & 6 & 3 & & & & \\
\hline Supra. + Subs. & 5 & 8 & 5 & 4 & 3 & 2 & & & & \\
\hline Supra. + Infra. + Subs. & 1 & 7 & 4 & 1 & 2 & 1 & & & & \\
\hline w/ Subs. tears & 7 & 15 & 12 & 11 & 6 & 5 & $56(97 \%)$ & $2(3 \%)$ & 58 & $<0.001$ \\
\hline w/o Subs. tears & 51 & 4 & 4 & 18 & 6 & 5 & $88(75 \%)$ & $30(25 \%)$ & 118 & \\
\hline
\end{tabular}

Abbreviations: Infra: infraspinatus; Subs: subscapularis; Supra: supraspinatus; LHB: long head of the biceps.

ders) of LHB pathology was defined as biceps instability. Seventy-nine percent of cases (15/19 shoulders) with Type 2 biceps lesions had torn subscapularis tendons, versus $75 \%$ (12/16 shoulders) of Type 3 biceps lesions (Table 2 ).

\section{Treatment for LHB pathology}

Nineteen of 58 shoulders with Type 1 lesions received limited debridement. For the 19 shoulders with Type 2 lesions, debridement was performed in 14 ; the remaining five shoulders received relocation and repair of the transverse humeral ligament. For the 16 shoulders with biceps dislocation (Type 3), 11 received tenotomy, and five received tenodesis. For Type 4 lesions, debridement or partial resection was performed in 15 of 29 shoulders, tenodesis in nine shoulders, and tenotomy in five shoulders. Tenodesis was performed in a majority of cases of a completely torn LHB (8/12 shoulders). For Type 6 lesions, debridement was performed in seven shoulders (two SLAP type I, three SLAP type III and two SLAP type IV); the remaining three shoulders with SLAP type II lesions received suture anchor repair. The two cases of SLAP type IV lesions presented with tears of $<30 \%$ of the superior labrum, so only excision of the labrum was performed. In total, one hundred and seven shoulders $(74 \%)$ underwent surgery to address simultaneous lesions of the LHB and rotator cuff tendons.

\section{DISCUSSION}

Injury to the LHB is often responsible for shoulder pain before or after surgery for RCTs. Successful 
rotator cuff surgery therefore depends upon the detection and proper treatment of concomitant biceps lesions. Two different classification systems to describe LHB lesions were presented in 3 different studies, ${ }^{(2,6,7)}$ but they are complex and difficult to apply in clinical use. Chen et al. modified the classification of LHB pathology associated with RCTs into five types of biceps lesions: tendinitis (Type 1), subluxation (Type 2), dislocation (Type 3), partial tear (Type 4), and complete rupture (Type 5). ${ }^{(2)}$ Unfortunately, these five types of lesion were confined to the biceps groove and did not include the biceps long head tendon anchor. However, in our practice, we observed that a small portion of RCTs occur with concomitant SLAP lesions.

A SLAP lesion was viewed as a distinct clinical entity after its first report by Snyder et al. in $1990{ }^{(8)}$ The literature suggests that the incidence of SLAP lesions in patients undergoing shoulder arthroscopy ranges from $6-12 \% .{ }^{(9)}$ These injuries are classically described as isolated lesions in young throwing athletes. However, a study of 139 patients with SLAP lesions suggested that most (123/139) were associated with other intraarticular lesions. ${ }^{(10)}$ Snyder et al. reported that $29 \%$ of SLAP lesions were associated with partial-thickness tears of the rotator cuff, and $11 \%$ were associated with full-thickness tears. ${ }^{(8)}$ In Kim et al's multivariate analysis, type I SLAP lesions were typically associated with RCTs; type II SLAP lesions were specifically associated with supraspinatus tears in patients $>40$ years. ${ }^{(10)}$

Although a variety of mechanisms create SLAP lesions, Maffet et al. suggested that the most common etiology was traction on the biceps tendon. ${ }^{(11)} \mathrm{A}$ study of 104 cadavers found that degenerative changes in the biceps tendon occurred mainly in the distal bicipital groove and near the origin of the tendon from the superior part of the glenoid labrum. ${ }^{(12)}$ This study identified the sites most subject to tendon rupture. A subsequent study using a biomechanical model elucidated the relationship of inferior subluxation of the glenohumeral joint and type II SLAP lesions. ${ }^{(13)}$ An alteration in the loading direction of the LHB relative to the fibers at the superior glenoid may predispose the biceps/labrum complex to failure. This mechanism may also explain the development of SLAP lesions in biceps subluxation/dislocation as a consequence of a torn subscapularis tendon. Further, Savoie et al. presented a mechanism to explain the sequence of SLAP lesions and RCTs. ${ }^{(14)}$ In their theory, the logical mechanism, both traumatic and chronic, causes a specific lesion involving the anterior superior corner of the glenohumeral articulation to produce an anterior superior slide of the shoulder. As the instability continues, the rotator cuff becomes irritated, causing symptoms that may mimic an impingement syndrome. So the concept of anterior superior labral tear and anterior supraspinatous (cuff) tear could also explain the cause of concomitant RCTs and SLAP lesions. Morgan et al. also found lesion-specific RCTs in SLAP lesions with shoulder instability and secondary pseudolaxity. ${ }^{(15)}$ They posited that microinstability in the setting of SLAP lesions may precipitate a secondary strain injury to the rotator cuff. Although this had not been definitely proven, it is supported by several cadaveric studies as well as clinical evidence. So, in brief, whether a SLAP lesion is the consequence or cause of an RCT, it is definitely one of the most important findings, if present, during rotator cuff repairs.

Although the incidence of SLAP lesions in patients receiving surgical treatment for RCTs was relatively lower $(6 \%)$ in our study than that of other types of LHB pathology (Types 1-5, 76\%), SLAP lesions represent a unique associated pathological change seen in conjunction with RCTs. In the modified 6-type classification we devised for LHB pathology, the most common lesion was Type 1 (40\%). We noted a slightly higher incidence of LHB pathology in our patient group compared with that of Chen et al. (82\% vs. $76 \%$, respectively). ${ }^{(2)}$ This difference may result from our enrollment of SLAP lesions, which were not included in the five-type classification and may have been regarded as a "normal biceps tendon" in Chen's study. Viewing the SLAP lesion as a subgroup of LHB pathology, we found that patients with chronic (>3 months), massive $\left(>5 \mathrm{~cm}^{2}\right)$, and multiple or subscapularis tendon involvement in RCTs had a significantly higher possibility of concomitant LHB pathology (Tables 1 and 2). That means that when performing open or arthroscopic rotator cuff repair, surgeons should carefully evaluate the biceps tendon both in the biceps groove and at its insertion at the labrum, particularly in RCT cases with chronic, massive, and multiple or subscapularis tendon involvement.

Surgical treatment for concomitant LHB pathology during rotator cuff repair includes debridement, 
tenotomy or tenodesis. The decision depends on the type or nature of the biceps lesion, the patient's age and activity level, cosmetic concerns, and tolerance of rehabilitation. The surgical management of concomitant rotator cuff and SLAP lesions remains controversial, especially in middle-aged patients. Several recent studies have reported clinical outcomes after simultaneous surgical treatment for these two disorders, mostly for SLAP type II lesions. Voos et al. reported good clinical outcomes, restoration of motion and a high degree of patient satisfaction after combined arthroscopic rotator cuff and labral repairs. ${ }^{(16)}$ Franceschi and colleagues reported a randomized control trial that found no advantage in repairing a type II SLAP lesion when associated with an RCT in patients $>50$ years old. ${ }^{(17)}$ In this patient group, they suggested that performing a tenotomy for SLAP type II lesion in RCTs repair could provide a better clinical outcome. Abbot et al. reported improved satisfaction and functional outcomes for patients $>45$ years old with concomitant arthroscopic rotator cuff repair and debridement of type II SLAP lesions, compared with those who underwent simultaneous rotator cuff and type II SLAP lesion repair. ${ }^{(18)}$ However, currently there is no definite recommendation for treating concomitant SLAP lesions in RCTs. Nevertheless, stabilizing the labral tear should theoretically decrease the tensile load on the rotator cuff. Levy and colleagues studied the effect of RCTs on surgical outcomes after type II SLAP lesion repair in patients $<50$ years. ${ }^{(19)}$ They found that once the SLAP lesion is repaired and the glenohumeral stability restored, the presence of a rotator cuff lesion will not affect the surgical outcome. The three patients with SLAP type II lesions in our study all presented with massive rotator cuff tears. Although they were older than 45 years $(48,53$ and 58 years), we still repaired the SLAP lesions with suture anchors instead of debridement alone, to restore glenohumeral joint stability and improve the surgical outcomes of the rotator cuff repair. Another report compared concomitant arthroscopic repairs of SLAP lesions and RCTs with isolated arthroscopic rotator cuff repair. ${ }^{(20)}$ The study concluded that in middle-aged patients, the results of combined SLAP lesion and rotator cuff repair were comparable to rotator cuff repair alone. In other words, if SLAP lesions are identified and treated properly during the surgical treatment of RCTs, the outcome can equal that of rotator cuff repair alone. Therefore, proper management of SLAP lesions, if they exist, is the key to successful treatment of complicated RCTs.

As a retrospective and observational design, our study had two limitations. First, because of the complex structure of shoulder, combined disorders often cannot be explained by a single mechanism. In our study, many patients presented with shoulder disorders other than RCTs and LHB pathology; we did not include these disorders. Surgeons who perform shoulder arthroscopic rotator cuff repair should also pay attention to structures other than LHB pathology. Failure to identify and address other shoulder lesions may lead to unsatisfactory surgical outcomes. Second, the surgical outcomes of patients with LHB pathology and RCTs were not presented in our study result. The low follow- up rate and incomplete records for shoulder function and symptoms in our patients after surgical treatment made collecting surgical outcomes problematic. Future studies should include these data, as well as longer follow- ups.

\section{Conclusion}

This study is the first observational report to include SLAP lesions in the classification of LHB pathology in patients with RCTs. This revised 6-type classification is a more comprehensive arthroscopic depiction of the spectrum of LHB pathology. We hope that the concept of 6-type LHB pathology in RCTs will remind arthroscopic surgeons of the important labrum-biceps complex when doing rotator cuff repair, so as to ensure proper surgical management.

\section{REFERENCES}

1. Peltz CD, Perry SM, Getz CL, Soslowsky LJ. Mechanical properties of the long-head of the biceps tendon are altered in the presence of rotator cuff tears in a rat model. J Orthop Res 2009;27:416-20.

2. Chen $\mathrm{CH}$, Hsu KY, Chen WJ, Shih $\mathrm{CH}$. Incidence and severity of biceps long head tendon lesion in patients with complete rotator cuff tears. J Trauma 2005;58:1189-93.

3. Gill HS, El Rassi G, Bahk MS, Castillo RC, McFarland EG. Physical examination for partial tears of the biceps tendon. Am J Sports Med 2007;35:1334-40.

4. Miller C, Savoie FH. Glenohumeral abnormalities associated with full-thickness tears of the rotator cuff. Orthop Rev 1994;23:159-62.

5. Gartsman GM, Taverna E. The incidence of glenohumeral 
joint abnormalities associated with full-thickness, reparable rotator cuff tears. Arthroscopy 1997;13:450-5.

6. Burkhead WZ Jr, Arcand MA, Zeman C, Habermeyer P, Walch G. The biceps tendon. In: Rockwood C Jr, Matsen FA III, eds. The Shoulder. 2nd ed. Philadelphia, PA: WB Saunders, 1998:1009-63.

7. Habermeyer P, Walch G. The biceps tendon and rotator cuff disease. In: Burkhead WZ Jr, ed. Rotator Cuff Disorders. Media, PA: Williams \& Wilkins, 1996:142-59.

8. Snyder SJ, Karzel RP, Del Pizzo W, Ferkel RD, Friedman MJ. SLAP lesions of the shoulder. Arthroscopy 1990;6:274-9.

9. Snyder SJ, Banas MP, Karzel RP. An analysis of 140 injuries to the superior glenoid labrum. J Shoulder Elbow Surg 1995;4:243-8.

10. Kim TK, Queale WS, Cosgarea AJ, McFarland EG. Clinical features of the different types of SLAP lesions: an analysis of one hundred and thirty-nine cases. J Bone Joint Surg Am 2003;85:66-71.

11. Maffet MW, Gartsman GM, Moseley B. Superior labrumbiceps tendon complex lesion of the shoulder. Am J Sports Med 1995;23:93-8.

12. Refior HJ, Sowa D. Long tendon of the biceps brachii: sites of predilection for degenerative lesions. J Shoulder Elbow Surg 1995;4:436-40.

13. Bey MJ, Elders GJ, Huston LJ, Kuhn JE, Blasier RB, Soslowsky LJ. The mechanism of creation of superior labrum, anterior, and posterior lesions in a dynamic biomechanical model of the shoulder: the role of inferior subluxation. J Shoulder Elbow Surg 1998;7:397-401.

14. Savoie FH III, Field LD, Atchinson S. Anterior superior instability with rotator cuff tearing: SLAC lesion. Orthop Clin North Am 2001;32:457-61

15. Morgan CD, Burkhart SS, Palmeri M, Gillespie M. Type II SLAP lesions: three subtypes and their relationships to superior instability and rotator cuff tears. Arthroscopy 1998;14:553-65.

16. Voos JE, Pearle AD, Mattern CJ, Cordasco FA, Allen AA, Warren RF. Outcomes of combined arthroscopic rotator cuff and labral repair. Am J Sports Med 2007;35:1174-9.

17. Franceschi F, Longo UG, Ruzzini L, Rizzello G, Maffulli N, Denaro V. No advantages in repairing a type II superior labrum anterior and posterior (SLAP) lesion when associated with rotator cuff repair in patients over age 50: a randomized controlled trial. Am J Sports Med 2008;36: 247-53.

18. Abbot AE, Li X, Busconi BD. Arthroscopic treatment of concomitant superior labral anterior posterior (SLAP) lesions and rotator cuff tears in patients over the age of 45 years. Am J Sports Med 2009;37:1358-62.

19. Levy HJ, Schachter AK, Hurd JL, Lassen B, Panagopoulos G. The effect of rotator cuff tears on surgical outcomes after type II superior labrum anterior posterior tears in patients younger than 50 years. Am J Sports Med 2010;38:318-22.

20. Forsythe B, Guss D, Anthony SG, Martin SD. Concomitant arthroscopic SLAP and rotator cuff repair. J Bone Joint Surg Am 2010;92:1362-9. 


\section{旋轉袖破裂病患二頭肌長頭肌腱病變之分析}

\section{陳建豪陳志華張智翔蘇君毅王坤全王宜君 劉獻道 游重銘 徐郭堯 ${ }^{1}$}

背景：二頭肌長頭肌腱之病變常與旋轉袖破裂相伴發生。SLAP (superior labral anterior-posterior) 病灶亦是可能伴行之損傷，但先前的分類卻未曾提及之。本研究之目的爲將 SLAP 病灶納入與旋轉袖破裂伴存的二頭肌長頭肌腱病變之範尌, 同時定義 SLAP 病 灶在旋轉袖破裂扮演之角色。

方 法: 回顧性地統計及分析 176 個旋轉袖完全破裂且接受手術治療之臨床病例資料。術中 以肉眼或是關節鏡檢視二頭肌長頭肌腱並記錄之。我們提出一個新的分類來描述及 分析二頭肌長頭肌腱之病變, 一共包含六種：肌腱炎、半脱位、脱位、部分断裂、 完全斷裂及 SLAP 病灶。再以統計學方式分析二頭肌長頭肌腱病變之發生與不同特 性之旋轉袖破裂的關係。

結 果：在旋轉袖破裂手術中我們發現有 $33 \%$ 的病患存在第一型（肌腱炎）的二頭肌長頭肌 腱之病變，11\% 的病患存在第二型（半脱位）病變，9\%的病患存在第三型（脱位） 病變, $16 \%$ 的病患存在第四型 (部分斷裂) 病變, $7 \%$ 的病患存在第五型 (完全断裂) 病變，6\% 的病患存在第六型（SLAP 病灶）病變。剩下的 $18 \%$ 之病患其二頭肌長頭 肌腱没有明顯之病變。同時我們發現二頭肌長頭肌腱病變之發生較常與有以下幾個 性質的旋轉袖肌腱破裂相伴隨: 慢性 (大於三個月) 、多條的旋轉袖破裂、破裂面積 大於 5 平方公分以及肩胛下肌肌腱破裂。在這些病患中, $74 \%$ 的病患同時接受二頭 肌長頭肌腱病變及轉袖破裂的手術治療。

結 論：慢性、大範圍、多條或是影響肩胛下肌肌腱的旋轉袖破裂絕大多數的病例會合併二 頭肌長頭肌腱病變。SLAP 病灶在我們所提出的分類中是屬於二頭肌長頭肌腱病變的 一環，若存在的話理應在旋轉袖破裂修補手術中同時依照病患的臨床狀況給予適當 的治療。

(長庚醫誌 2012;35:263-70)

關鍵詞：二頭肌長頭肌腱，旋轉袖破裂，SLAP 病灶

長庚醫療財團法人基隆長庚紀念醫院 骨科; 長庚醫療財團法人林口長庚紀念醫院 骨科部 ; 長庚大學 醫學院 受文日期：民國100年7月11日；接受刊載：民國100年12月7日 通訊作者: 陳志華醫師, 長庚醫療財團法人基隆長庚紀念醫院 骨科。基隆市204安樂區麥金路222號。

Tel: (02)24313131轉2613; Fax: (02)24332655; E-mail: afachen@doctor.com 